\title{
En mujeres, la ganancia de peso se asoció a una disminución en la calidad de vida
}

A prospective Study of weight change and health-related quality of life in women.

Fine JT, Colditz GA, Coakley EH et al. JAMA 1999; 282 : 2136-42.

\section{Objetivo}

Analizar la asociación entre modificaciones del peso corporal y la calidad de vida como percepción de salud en mujeres.

\section{Diseño}

Estudio de Cohorte prospectiva.

\section{Lugar}

Se utilizaron las encuestas realizadas desde 1992 hasta 1996 del estudio "The Nurses'Health Study".

\section{Pacientes}

Un total de 40098 enfermeras de 46 a 71 años en 1992, agrupadas por edad e índice de masa corporal (en inglés Body mass index: BMI) al inicio del estudio.

\section{Evaluacion del factor pronóstico}

Se definieron 3 categorías según el comportamiento del peso corporal:

Perdedoras de peso: aquellas que perdieron 2,25 Kg. o más entre 1992 y 1996 y no habían ganado 2.25 kg o más en los períodos de 2 años intermedios.

Ganadoras de peso: ganaron $2.25 \mathrm{~kg}$ o más entre 1992 y 1996 y no habían perdido $2.25 \mathrm{~kg}$ o más en los períodos de 2 años intermedios. Peso estable: mujeres que en 1996 tenían una diferencia no mayor a $2,25 \mathrm{Kg}$. respecto al inicial en 1992. No habían perdido ni ganado 2.25 $\mathrm{kg}$ o más en los períodos de 2 años intermedios.

\section{Medición de Resultado Principal}

La calidad de vida se midió utilizando el SF-36. Se registraron las modificaciones en 7 dimensiones: función física, vitalidad, dolor corporal, limitación de la función por problemas físicos o emocionales, función social, y salud mental.

\section{Resultados}

Mantuvieron el peso 15602 mujeres (39\%), ganaron entre 2,25 y $9 \mathrm{Kg}$. 15160 mujeres (38\%) y perdieron entre 2,25 y $9 \mathrm{Kg} 6667(17 \%)$. La ganancia de peso se asoció con deterioro en la función física y la vitalidad así como con aumento en el dolor corporal sin importar cuál fuera el peso inicial. El desarrollo de limitación funcional por problemas físicos presentó un odds ratio de 2.05 (IC $95 \%=1.69-2.49$ ) para aquellas mujeres que ganaron $9 \mathrm{~kg}$. o más. Perder peso en mujeres con sobrepeso inicial se asoció a mejoría en la función física y vitalidad así también con una disminución en el dolor corporal. Las modificaciones en el peso se asociaron más a modificaciones en las dimensiones físicas que en las de salud mental. El impacto en la modificación de peso fue tan importante en el estrato de mujeres jóvenes como en el de mayores de 65 años.

\section{Conclusiones}

Ganar peso se asoció a deterioro en la función física y la vitalidad en todos los grupos analizados. Perder peso en caso de sobrepeso inicial se asoció a mejoría en la función física y la vitalidad.

\section{COMENTARIO}

El sobrepeso y la obesidad se relacionan con mayor mortalidad global y elevada incidencia de diabetes, hipertensión, enfermedad cardiovascular, artrosis y algunos tumores. En estudios previos se encontró asociación entre mayor peso corporal y menor calidad de vida ${ }^{1}$. En nuestro medio, en un estudio sobre personas que concurrieron a un programa de control de peso, se describieron dificultades identificadas por los pacientes asociadas al sobrepeso ${ }^{2}$. Si bien era una población seleccionada, dado que concurrían voluntariamente a un programa, las dificultades referidas más frecuentemente fueron: 1) ropa $(82,3 \%$ de las mujeres y $69 \%$ de los hombres) 2) vida diaria ( $42 \%$ de mujeres y $51 \%$ de los varones) 3) recreación (37\% de las mujeres y $43,6 \%$ de los hombres).

El "Nurses'Health Study" se trata de una Cohorte de 121700 en- fermeras entre 30 y 55 años que completa un cuestionario sobre factores de riesgo para cáncer y enfermedad cardiovascular cada 2 años desde 1976. Se logró un seguimiento de más del $90 \%$ de la cohorte a los 20 años. En 1992 y 1996, se administró además el SF-36 para medir calidad de vida. Por el hecho de ser enfermeras, la validez externa * del trabajo disminuye pero la información resultante es muy valiosa a pesar de las limitaciones para generalizar los resultados. Los autores encontraron que el aumentar de peso aún en mujeres sin sobrepeso inicial, disminuía la calidad de vida. Si existía sobrepeso, adelgazar mejoraba la calidad de vida. Estos resultados reafirman las recomendaciones habituales de solicitar a las pacientes que eviten aumentar de peso, aunque no tengan sobrepeso. De acuerdo a los hallazgos de este estudio esa recomendación es válida aún para mujeres mayores de 65 años.

*Ver Glosario

\section{Dra. Marina Khoury}

Servicio de Clínica Médica. Centro Medicus. Capital Federal.

Docente de Metodología de la Investigación. Centro de Investigaciones Epidemiológicas. Academia Nacional de Medicina.

\section{Referencias}

1. Coakley EH, Kawachi Y, Manson JE et al.: Lower Levels of physical functioning are associated with higher body weight among middle ageg and older women. Int J 0 bes 1998 ; $22: 958-965$. 2. Saidler E, Saidler L, Regueiro A, García S: Aspectos Psicosociales de la Obesidad en un Programa de Control de Peso. Capital Federal: X Congreso Anual de la Sociedad Argentina de Medicina Interna General. 1999. Presentación de temas libres. 